\title{
Teacher's Listening in Teaching Mathematics Using an Open Approach
}

\author{
Kanjana Wetbunpot ${ }^{1}$, Narumol Inprasitha ${ }^{2}$ \\ ${ }^{1}$ Centre of Excellence in Mathematics, $\mathrm{CHE}$, Bangkok, Thailand \\ ${ }^{2}$ Faculty of Education, Khon Kaen University, Khon Kaen, Thailand \\ Email: wetbunpot crme@kku.ac.th
}

Received 23 June 2015; accepted 15 August 2015; published 19 August 2015

Copyright (C) 2015 by authors and Scientific Research Publishing Inc.

This work is licensed under the Creative Commons Attribution International License (CC BY). http://creativecommons.org/licenses/by/4.0/

(c) (i) Open Access

\section{Abstract}

The objective of this study was to analyze the effects of teachers' listening in teaching mathematics using an open approach on their teaching roles. The target group of this research study consisted of a mathematics teacher and 12 students of the first graders. The classroom used has continually been under the lesson study and open approach context. In this study, data were collected from observation and recording of teachers' listening behavior and their teaching roles. Descriptive analysis was employed in data analysis. Research findings indicated that teachers' listening during mathematics teaching by an open approach caused the teachers to play the teaching roles as follows: 1) teachers listened to stimulate the students to consider problems from the pictures and storytelling of the problem situations. Roles played by the teachers included presenting the situation pictures, telling stories about child playground activities, and asking students questions about the sources of their ideas; 2 ) teachers listened to collect the students' mathematical ideas. The roles played by the teachers included observing and recording the students' ideas and encouraging the students to show their thinking methods by asking them questions; 3 ) teachers listened to explain and compare the students' ideas expressed. The roles played by the teachers included discussing and expanding the students' ideas by posting supplementary media; and 4) teachers listened to summarize learning methods from the students' ideas. The roles played by the teachers included asking the students about what they had learned and writing down the lessons learned.

\section{Keywords}

Teacher's Listening, Open-Approach, Mathematics Teaching, Teaching Role

\section{Introduction}

Listening is essential for teachers to understand students' perspectives (Ball \& Cohen, 1999). There may be 
some ideas hidden behind the students’ problem-solving process. It is necessary to have a tool to understand what the students are doing, a reason behind their ideas, and to be able to adjust their procedures or ways of thinking to become acceptable. Teachers need to understand what the students say and do and to uncover the essence and sources of their ideas. The goal of teachers' listening is to find a way to develop students' ideas in a way that the whole classroom can see such ideas in detail (Arcavi \& Isoda, 2007). Teachers should use new methods relating to good characteristics of mathematics instruction, such as giving students willpower during conversation and inspecting students' challenging ideas and reasoning. During a conversation, a focus should be given on listening. Teachers should have good listening capabilities and listen to their students carefully in order to answer the students' questions to show that they understand the students. Listening is a key element in seeing students' ideas. It is deemed that teachers' listening to the students provides a learning opportunity. Effective listening and response to students' ideas are hard work. Listening is placed at the center of a teaching approach that gives students an opportunity to create knowledge or understanding on their own. Good listening is the beginning of effective mathematics teaching and the teachers' listening to students is a great contribution to effective mathematics teaching (Yackell, Cobb, \& Wood, 1990; Carpenter \& Fennema, 1992; Cobb et al., 1996; Davis et al., 1996; Boles et al., 1997; Franke \& Kazemi, 2001; Sherin, 2002; Muir, 2006; Empson \& Jacobs, 2008). Teachers' development of mathematics teaching by focusing on problem-solving process as a means to listen to students' ideas reflects an instructional method in which teachers give students an opportunity to freely express their mathematical concepts during their participation in solving mathematical problems. Thus, teachers have to learn to listen to the students' mathematical reasons and meanings. Doing so, the teachers will be able to analyze the students' behavior demonstrated during their problem-solving process. As a result, teachers can uncover the students' thinking or learning process and change their perspectives or beliefs towards the students that learning achievement is not the only thing that explains the students' learning process complexity (Inprasitha, 2003; Arcavi \& Isoda, 2007; Confrey, 1991). Outstanding characteristics of an open approach greatly contribute to the teachers' ability to give students a problem situation where there are many solution methods. Teachers can also benefit from the availability of many methods to find the problems most suitable to students' experiences. A discovery of new things as a result of collection of the students' mathematical ideas emerging in classroom and a comparison of various ideas eventually leads to further adjustment and development of the students' ideas (Sawada, 1997). The teaching process begins with teachers presenting to their students an open-ended problem situation. Then, students, either an individual student or a group of students, explore or investigate such problem situation and discuss among the group. After that, the teachers encourage classroom discussion on students' problem-solving ideas (Inprasitha, 2011). Apart from being a teaching method focusing on problem-solving process as a means to adopt listening to the students' ideas, the open approach relies on activities that the students have done or learned before. An important aspect of listening to students is to use referenced keywords when listening to what the students say while they are doing activities and the teachers need to take time to listen to the students' ideas. Therefore, the teachers' teaching method has be well developed (Inprasitha, 2014). This study was aimed at analyzing the effects of teachers' listening in teaching mathematics using an open approach on their teaching roles.

\section{Scope of Research}

The target group of this research consisted of a mathematics teacher and 12 students of the first graders of Khamkhoo Pittayasan School located in Khon Kaen Province. The teacher has had 9 years of practical experiences in lesson study and open approach. In terms of theoretical experiences, the teacher has regularly participated in academic conferences to apply the knowledge obtained to the practical aspects. With respect to content, this research involves addition where students are aware that if they have to deal with two digit addition, they have to add to make a group of 10's first, and then add beyond such group of 10's. The teacher presented a problem situation in which mathematical content was hidden, making it impossible to have a direct access to the mathematical content. However, students were able to access such content by means of solving the problem on their own with the teacher's support and assistance. The teacher, thus, had to understand the structure of mathematical content in order to be able to manage the instruction and enable students to solve the problem on their own (Inprasitha, 2014). 


\section{Research Methodology}

In this research study, the researcher and research assistant met to determines the roles and duties of the researcher and research assistant in collecting data on teaching method of the teacher using an open approach. The researcher was responsible for making notes of teacher-related observations, such as the teacher's presentation before the students began the activities, teacher's participation in student discussion during the activities, teacher's roles and presentation in interpreting the students' work, and teacher's presentation in relation to classroom discussion. The research assistant was responsible for video and sound recording.

\section{Data Analysis}

This research was aimed at analyzing teachers' listening in mathematics classroom where an open approach with a focus on problem-solving process was used. Such teaching method was modified from theoretical frameworks developed by Empson \& Jacobs (2008), and Inprasitha (2014) as described in detail below.

Step 1: Teacher presenting a problem situation: after the situation is presented, there may be some students not understanding what the teacher wants them to do. Thus, in order to help the students to understand what the problem means, the teacher should create a classroom context to promote good listening by stimulating the students to consider the same issue, adding concrete information, and giving an example that does not limit the students' ways of thinking about how to solve the problem. This means that the teacher's listening should stimulate the students' access to a mathematical problem presented to them.

Step 2: Teacher observing and making notes of the students' problem-solving methods: adoption of an open approach focusing on problem-solving process is meant to encourage each student to express his/her ideas. The teacher should be careful not to advise the students, but pose questions to stimulate the students to try to solve the problem or try to investigate or search for more data concerning the problem situation. The teacher moves closer to the students before beginning the listening process, tries to observe/note the "students' ideas" developed during the problem-solving process. The teacher pays attention to seek the significance of the content listened by focusing on understanding the students' main idea rather than details. This means that the purpose of the teacher's listening is to collect the students' mathematical ideas.

Step 3: Teacher having the students present, discuss, and compare their ideas: the teacher should organize the students' ideas to give them an opportunity to present, discuss, and compare the ideas for a learning opportunity of the whole class. During the conversation, the teacher should allow sufficient time for the discussion, encourage the students to freely express their ideas, analyze what the students heard by giving other students a chance to ask the students who give a presentation questions to, classify the students' ideas for the purpose of discussion and comparison for "learning benefits of the whole class", and expand the discussion results regarding the students' ideas by using "supplementary media.” This means that the purpose of the teacher's listening is to discuss and compare the students' ideas.

Step 4: Teacher summarizing the students' ideas and learning methods: the teacher collects all of the students' ideas and stimulates them to confirm their work by focusing on the lesson goal in order to lead to a summary of the students' ideas and learning methods. The teacher can remember important details from the conversations with the students, sum up the significance of the ideas heard, connect the students' ideas, and connect with various aspects of the problem situation, put in order the methods used by the students in justifying their problem-solving process, arrange the students' ideas, and summarize the students' learning in order to apply the students' ideas and learning to the next class. Thus, the teacher's listening in this aspect is aimed at summarizing the learning methods from the students' ideas.

\subsection{Teacher's Listening in Teaching Mathematics Teaching Using an Open Approach}

An analysis of teacher's listening in mathematics teaching from the observation form detailing the teacher's listening to students during mathematics teaching using an open approach with a focus on problem-solving process under the learning unit of addition with a total time of 12 hours and a total of 12 activities revealed that the teacher's listening behavior during the mathematics teaching by an open approach was as follows: [1] teacher stimulating the students to consider a problem from pictures and stories about the problem situation (12 activities); [2] teacher collecting the students' mathematical ideas (12 activities); [3] teacher explaining and comparing the students' ideas expressed (12 activities); and [4] teacher summarizing the learning methods based on the 
students' ideas (10 activities), as shown in the chart below (Figure 1).

\subsection{An Example}

Activity 1: Child Playground (Figure 2).

Lesson Goal: To enable students to understand and be able to solve an addition problem situation.

It was found that the teacher's listening behavior in mathematics teaching by the open approach was as follows: 1) the teacher listened to stimulate the students' access to the mathematical problem by means of storytelling and pictures of the problem situation; 2) the teacher listened to collect the students' mathematical ideas; 3) the teacher listened to discuss and compare the students' ideas expressed; and 4) the teacher listened to summarize learning methods from the students' ideas, as shown in detail below.

1) In the step of presentation of a problem situation, the teacher listened to stimulate the students' access to the mathematical problem by means of storytelling and pictures of the problem situation. Teaching roles played by the teacher were as follows:

a) Teacher showing pictures of the situation and telling stories about playground activities.

"There are nine children playing in a sand tray and the other four children playing with a slider. How many children are there in total?”

b) Teacher asking students a question concerning the source of answer no. 13

- Teacher: How do you know?

- Student: Adding to make 10 first and then adding 3.

2) In the step of observation and taking note of the students' problem-solving, the teacher listened to the students in order to collect their mathematical ideas. Teaching roles played by the teacher were as follows:

a) Teacher observing and taking note of the students' ideas (Figure 3).

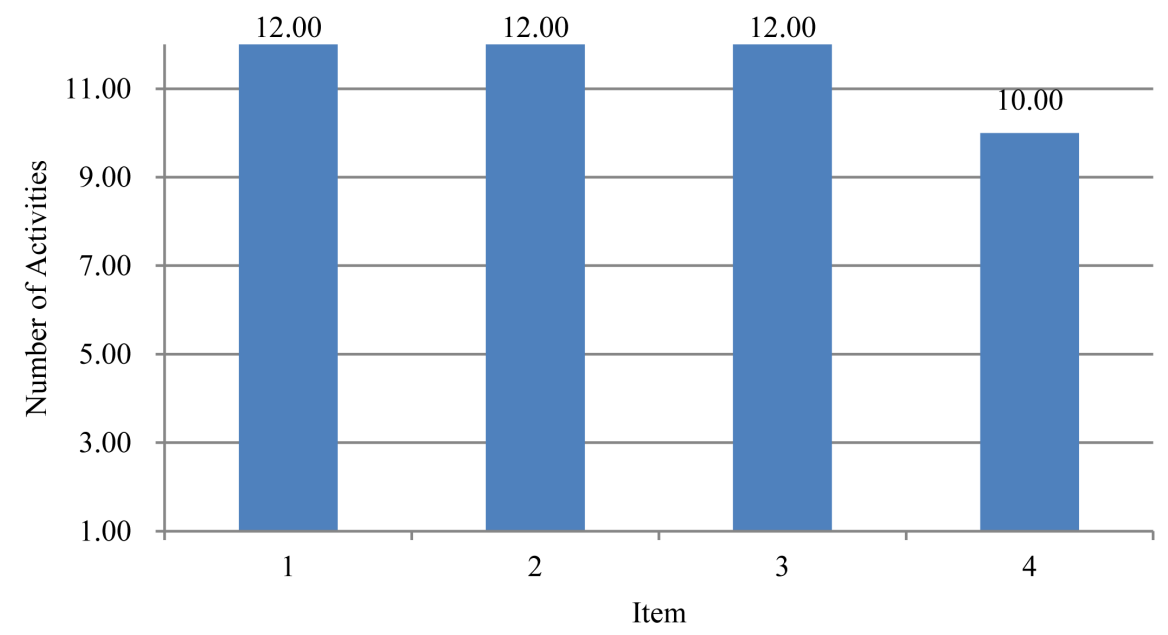

Figure 1. Teacher's listening behavior during mathematics teaching.

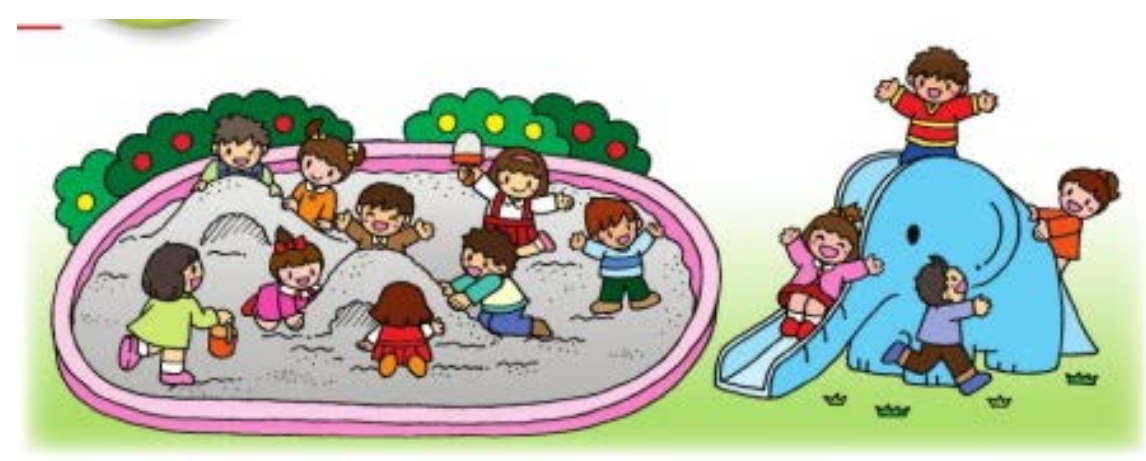

Figure 2. Child playground on page 77. 

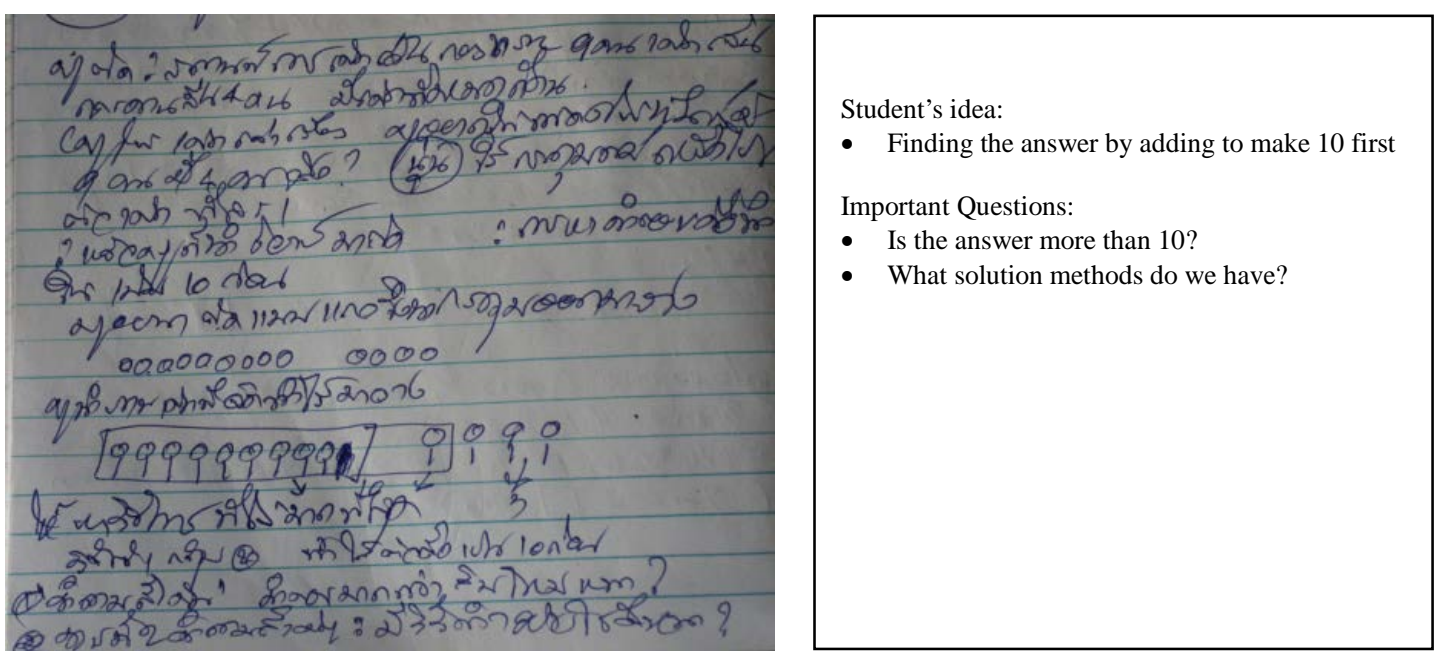

Figure 3. Teacher's notes on child playground activities.

b) Teacher encouraging students to show their thinking method by asking them a question as follows:

- Teacher: What do you do with the blocks?

- Student: Lay each block over the child in the situation picture.

- Then, put the blocks in the track and make circles around the children.

3) In the step of discussion and comparison of the students' ideas, the teacher listened to the students in order

to discuss and compare the students' ideas expressed. Teaching role played by the teacher was as follows:

Teacher discussing and expanding the students' idea by posting supplementary media as follows:

- Teacher: Why did you add one more?

- Student: Because I want to make it equal 10.

- Teacher: (Posting supplementary media to expand the students' idea) “Add 1 to 9 to make it equal 10.” Then, what's next?

- Student: Combine 10 and 3 together to make 13.

- Teacher: (Posting supplementary media to expand the students' idea) "10 and 3 equal 13." Where did 3 come from?

- Student: (Walking out to point at the picture of a group of four children)

4) In the step of summarization of the students' ideas, the teacher listened to students in order to sum up a learning method based on the students' ideas. Teaching roles played by the teacher were as follows:

a) Teacher asking students questions about what they have learned from the child playground activities as follows:

- Teacher: What have we learned from this lesson?

- Student: We have learned about adding to make 10 first. Then, we combine 10 with 3.

- Teacher: (Writing down what the student said and asking the class if there were any other things learned)

- Student: We have learned how to add up numbers to make 10 first.

- Teacher: Is there anything else?

- Student: Put blocks in the track. There are nine units and we add one more to make 10 . Then, move from one-digit number to two-digit number.

b) Teacher summing up what the class has learned from the students' wording as follows:

- Add to make 10 first. Then, combine 10 with 3.

- Add up numbers to make 10 first.

- Put blocks in the track. There are nine units and we add one more to make 10.

- Then, move from one-digit number to two-digit number.

\section{Conclusion}

As mentioned above, teachers' listening in mathematics teaching is essential for understanding students' perspectives. Teachers need to pay close attention to what the students are saying and doing in order to uncover the 
sources and essence of their ideas. However, we are usually used to the learning process and understanding that we regularly practice. We need to expand matters that we do not give importance to by attempting to eliminate what we are well aware of, which may at times obstruct our ability to understand the students' perspectives; thus, an important component of learning to listen to students is “not to learn mathematics.” Moreover, teachers' listening promotes creation of teaching concepts based on improvement of conditions necessary to long-term development of the teaching profession.

\section{Acknowledgements}

This research study was (partially) supported by the Centre of Excellence in Mathematics, the Commission on Higher Education, Thailand.

\section{References}

Arcavi, A., \& Isoda, M. (2007). Learning to Listen: From Historical Sources to Classroom Practice. Educational Studies in Mathematics, 66, 111-129. http://dx.doi.org/10.1007/s10649-006-9075-8

Ball, D. L., \& Cohen, D. K. (1999). Developing Practice, Developing Practitioners toward a Practice-Based Theory of Professional Education. In L. Darling-Hammond, \& G. Sykes (Eds.), Teaching as the Learning Profession (pp. 3-32), Handbook of Policy and Practice, San Francisco, CA: Jossey-Bass.

Boles, K., Troen, V., \& Kamii, M. (1997). From Carriers of Culture to Agents of Change: Teacher-Initiated Professional Development in the Learning/Teaching Collaborative Inquiry Seminars. Chicago, IL: The Annual Meeting of the American Educational Research Association.

Carpenter, T., \& Fennema, E. (1992). Cognitively Guided Instruction: Building on the Knowledge of Students and Teachers. International Journal of Educational Research, 17, 457-470. http://dx.doi.org/10.1016/s0883-0355(05)80005-9

Cobb, P., Jaworski, B., \& Presmeg, N. (1996). Emergent and Sociocultural Views of Mathematical Activity. In Theories of Mathematical Learning (pp. 3-19). Hillsdale, NJ: Lawrence Erlbaum Associates.

Davis, B., Sumara, D. J., \& Kieren, T. E. (1996).Cognition, Co-Emergence, Curriculum. Journal of Curriculum Studies, 28, 151-169. http://dx.doi.org/10.1080/0022027980280203

Empson, S. B., \& Jacobs, V. J. (2008). Learning to Listen to Children’s Mathematics. In T. Wood (Series Ed.), \& P. Sullivan (Vol. Ed.), International Handbook of Mathematics Teacher Education, Vol. 1: Knowledge and Beliefs in Mathematics Teaching and Teaching Development (pp. 257-281). Rotterdam: Sense Publishers.

Franke, M. L., \& Kazemi, E. (2001). Teaching as Learning within Community of Practice: Characterizing Generative Growth. In T. Wood, B. S. Nelson, \& J. Warfield (Eds.), Beyond Classical Pedagogy: Teaching Elementary School Mathematics (pp. 47-74). Mahwah, NJ: Lawrence Erlbaum.

Inprasitha, M. (2003). A Reform of Mathematics Learning Process in Schools Focusing on Mathematical Processes. A Report of the Research Council, National Research Council of Thailand. KhonKaen: KhonKaen Publishing.

(2011). Problem Solving Classroom in Lesson Study and Open Approach Context. Proceedings of the 16th Annual Meeting in Mathematics (AMM 2011), Thailand, 20-28.

Inprasitha, M. et al. (2014). Explanations of How to Use the First Grade Mathematics Textbooks. KhonKaen: KhonKaen University Publishing House.

Muir, T. (2006). What Does Effective Teaching for Numeracy Look Like? The Design of an Observation Schedule. In P. Grootenboer, R, Zevenbergen, \& M. Chinnappan (Eds.), Identities, Cultures, and Learning Spaces (Proceedings of the 29th Annual Conference of the Mathematics Education Research Group of Australasia, Canberra, 368-375). Sydney: MERGA.

Sawada, T. (1997). Developing Lesson Plans. In: J. Becker, \& S. Shimada (Eds.), The Open-Ended Approach: A New Proposal for Teaching Mathematics (pp. 1-9). Reston, VA: National Council of Teachers of Mathematics.

Sherin, M. (2002).When Teaching Becomes Learning. Cognition and Instruction, 20, 119-150. http://dx.doi.org/10.1207/S1532690XCI2002_1

Yackell, E., Cobb, P., \& Wood, T. (1990). The Interactive Constitution of Mathematical Meaning in One Second Grade Classroom: An Illustrative Example. Journal of Mathematical Behaviour, 11, 458-477. 